http://jmscr.igmpublication.org/home/ ISSN (e)-2347-176x ISSN (p) 2455-0450

crossref DOI: https://dx.doi.org/10.18535/jmscr/v7i10.82

Journal Of Medical Science And Clinical Research

\title{
Marital dissatisfaction and perceived social support as predictors of depression among married individuals
}

Authors

\section{Okoli, Paul Chibuike, PhD ${ }^{{ }^{*}}$, Ezeme, Mark Sunday, MBBS, FMC Psych. ${ }^{2}$, Ofojebe, Chukwuma, Philip, PhD $^{3}$}

${ }^{1}$ Department of Internal Medicine ESUT College of Medicine, Enugu State University of Science and Technology, Enugu-Nigeria

${ }^{2}$ Department of Internal Medicine ESUT College of Medicine, Enugu State University of Science and

Technology, Enugu-Nigeria

${ }^{3}$ Azikiwe University, Awka. Anambra State- Nigeria

*Corresponding Author

Okoli, Paul Chibuike, PhD.

\begin{abstract}
This study investigated marital dissatisfaction and perceived social support as predictors of depression among married individuals. The participants for this study comprised of 276 members of Catholic Men Organization (CMO) and Catholic Women Organization (CWO) of Awka Diocese, selected through the use of simple random sampling technique. Their age ranged from 24 to 55 years, with a mean of age of 46.12 and a standard deviation of 18.34. Instruments administered on them included Index of Marital Satisfaction (IMS), Depression subscale (Scale D) of Symptom Distress Checklist-90 (SCL-90), and Multidimensional Scale of Perceived Social Support (MSPSS). Multiple Linear Regression Statistic was used to analyze the data collected. Result showed that the first hypothesis was not confirmed, and that the last three hypotheses were confirmed. Based on these findings, it revealed that while marital dissatisfaction was found not to be a factor positively predicting depression among married individuals in Awka Diocese, social support domains (e.g. family, friends, and significant others) were found to negatively predict depression among married individuals. Therefore, based on these results, it was recommended that married individuals should not only ensure that they seek for ways of making their marital experiences more positive in other to checkmate marital dissatisfaction, they should also endeavour to see that the three domains of social support present in their lives are positive as well. This should be so, for such positive nature of these variables will go a long way in preventing them from presenting with depression.
\end{abstract}

Keywords: Marital dissatisfaction, perceived social support, depression, married individuals.

\section{Introduction}

Literature have established that unhappy marriages were a potent risk factor for major depressive disorder for both men and women (Weissman, 1987); Hashmi, Khurshid and Hassan
(2007). Similarly, Cano and O'Learvy (2000) found that marital events resulted in a six-fold increase in the risk of clinical depression; and this increased risk remained after controlling for family and personal history of depression. The 
researcher's clinical practice in the psychiatric shows that $80 \%$ of depression cases referred to the psychology unit was men and women with distressed marriages. It then becomes necessary to embark on this study to establish whether marital dissatisfaction and perceived social support as the predictors of depression among married men and women.

Depression can be defined as a mental illness in which a person experiences deep, unshakable sadness and diminished interest in otherwise enjoyable in nearly all activities (Richard, 2004). According to WHO (2012) depression is a common mental disorder that present with depressed mood, loss of interest or pleasure, decreased energy, feelings of guilt, or low selfworth, disturbed sleep or appetite and poor concentration. Moreover, depression often comes with symptoms of anxiety. These problems can become chronic or recurrent and lead to substantial impairment in an individual's ability to take care of his or her everyday responsibilities. At its worst, depression can lead to suicide which translates to three suicide death every day. However, depression can be severe, moderate or mild.

The reason for this focus on depression is because depression appears to be on the increase. According to WHO (2016), common mental disorders are increasing worldwide. Between 1990-2013, the number of people suffering from depression and/ or anxiety increased by nearly $50 \%$, from 416 million to 615 million. Close to $10 \%$ of the world population is affected, and mental disorders account for $30 \%$ of the global non-fatal disease burden. Besides, the estimated cost scaling up treatment, primarily psychosocial counselling and antidepressant medication, amounted US\$147 billion.

However, depression appears to be a more common case seen almost on daily basis among married individuals. Besides, depression is one of the most common mental health disorders and is represented as an emerging public health problem (WHO, 2001), it is also ranked as the fourth disorder in the global burden of disease and by the year 2030, it is expected to be the highest disorder in high-income countries (WHO, 2001). Similarly, WHO (2016) alluding to the investing in treatment for depression and anxiety noted that depression and anxiety disorders cost the global economy US\$1 trillion each year; countries and development. Also, scientific evidence shows that depression alters cardiovascular immune and endocrine function, and these alterations are sufficient to enhance a variety of health threats. (Simonsick, Wallance, Blazer and Berkman, 1995); Glassman and Shapiro, 1998). More so, studies of depressed children revealed that they frequently had parents with a psychiatric illness, in particular depression (Beardlee, Bemporad, Keller and Kilerman, 1983).

Successful treatment of depression depends in part on predicting the likely stressor creating depression for married men and women. The treatment is both pharmacotherapy and psychotherapy, but the choice of either or both will depend at the level of the depression (mild, moderate or severe). According to literature, treatment of mild-to-moderate depression requires first: consider watchful waiting, assessing normally within two weeks. Secondarily, consider offering one or more low intensity psychosocial intervention, guilded by patient preference: guided self-help based on cognitive behavioural therapy (CBT) Cuijpers, Van Straten, Van Schaik, et al; (2009), NICE (2013). However, treatment of moderate-to-severe depression requires: offering antidepressant medication combined with high intensity psychological treatment for an individual with a chronic health problem and moderate depression, these should be high intensity psychological treatment alone in the first instance Uher, Payne, Pavlova et at; (2013) in young people combine CBT and newer antidepressant may be better, in the short term than either therapy alone, particularly with regard to the global functioning 16, make urgent psychiatric referral if the patient has active suicidal ideas or plans, is putting themselves or others at immediate risk of 
harm, is psychotic, severely agitated or is selfneglected. Electroconvulsive therapy (ECT) may be used to gain faster and short term improvement of severe symptoms after all other treatment option have failed, or when the situation is thought to be life-threatening (Huntley, Araya, Salisbury, 2012)

Essentially, the psychotherapy treatment will target enhancing the couple coping styles positively, cognitive restructuring, positive cognitive appraisals of self, environment and others, positive behavioural adjustment to enable couples combat their marital stressors among others.

Marriage is an established contract between two parties who become husband and wife. It is devoted to be a two-way process in which sharing and caring takes place at both ends. Marriage is contract/covenant between a man and a woman who is socially or ritually recognized which institutes rights and obligations between them as husband and wife. Marriage is said to be legal, formalised commitment which facilitates association in a network that could potentially provide social support and influences one's well being (Cotton, 1999). In African context, marriage is a social phenomenon in which two strangers, of two different families of orientation, agree to establish family of procreation (Dokpesi, 2013). Apart from procreation, some people marry because of other innumerable reasons ranging from social, economic and biological reasons. If one partner fails to meet up the other's intention or the other fails to achieve the objective of going into marriage, conflicting state would rise, resulting in marital dissatisfaction and possibly stress.

Marital dissatisfaction is the perceived level of unhappiness experienced by each spouse (Amato \& Previt, 2003). Similarly, Akanbi (2002) defined marital satisfaction as the extent to which partners in marriage have a sense of accomplishment or fulfilment of the mutual needs, goals and expectation in marriage. Marital dissatisfaction can also arise when the bread winner (especially the husband) is not meeting up with the demands of the wife or the family. Consequently, marital dissatisfaction may result in family break-up (Beach, Katz, Kim, \& Brody, 2003). Besides, Coyne and Benazon, (2001) observed that marital dissatisfaction seems to exert a significant psychological toll on many spouses, at the same time, there is much about the prospective effect of marital dissatisfaction on depression that remains poorly understood. Marital dissatisfaction has a lot of negative impacts on the couple which may include the following: It has a variety of effect on physical and emotional health. For example, it increases risk for destructive conflict patterns (Gottman 1998). It is associated with physiological reactivity (Levenson, Carstensen, and Gottman 1994), and leads to suppressed immune system functioning. Meanwhile, as the individual lacks the coping skill to handle his/her the effect becomes emotional misery. This is linked to sadness, irritability and diminished interest in sex as well as other depressive symptoms (Kiecolt-Glaser, Malarkey, and Chee 1993). Marital dissatisfaction leads to marital distress and relationship conflict. Hence, Hashmi, Khurshid and Hassan (2007), reported that marital distress and relationship also contribute to depression. Can one then say that depression may erupt among married couples as a result of dissatisfaction in the marriage, and social support? This is what this work set out to find out.

However, social support is factor that is likely to help couples to cope with psychopathological symptoms. According to Gabe, Bury, and Elston, (2004), social support is those aspects of social relationships that provide a sense of self-worth and offer resource in tackling life's troubles. Similarly, it is the emotional, instrumental and material support that members or a group in a social network provides. It involves both formal and informal social structures (Schuler and Vidmar, 1992). Gabe, Bury, and Elston, (2004) added that social support acts as a powerful mediating factor in a range of physical and mental health problems. It operates at different levels: 
emotional, instrumental and informational levels. Emotional support can reassure individuals that they are still cared for and given the opportunity to positively express their worries and negative feelings. Instrumental support is often essential in helping people get through day-by-day life, such as physical care, financial assistance or help with responsibilities like shopping. A number of studies have shown the importance of social support in helping people to control, adapt to and make better recoveries from a range of chronic illnesses including diabetes and heart disease (Zare, Hajizadeh and Ebrahimi, 2010) but the research on the impact of social support on psychological illness among married in Nigeria is still scanty, hence the need for this study.

The general purpose of this study is to determine if marital dissatisfaction and social support are among the predictors of depression among married individuals. Specifically, the study is aimed at determining:

1) If marital dissatisfaction predict depression among married men and women?

2) If social support predict depression among married men and women?

This research is theoretically and practically relevant. Theoretically, this study will help to widen the scope of our understanding on depression as it relates marital dissatisfaction and social support. Practically, this study will provide insight, which will help marriage counsellor in preparing intending couples, guiding couple, and enhance couple self-awareness of likely stressors and ways of coping with them.

Operational definition of terms.

Depression: This is a mood disorder characterized by persistent feeling of sadness and loss of interest in previous pleasurable activities among other symptoms as measured by Symptom Distress Checklist-90.

Social Support: This entails the emotional, instrumental and material support that members or a group in a social network provide or receive as measured by the Multidimensional Scale of Perceived Social Support.
Marital Dissatisfaction: This is a situation whereby married people are not contented with their marriage due to one problem or the other, or as a result of some unfulfilled needs as measured by Index of Marital Satisfaction.

\section{Methods \\ Study Design}

This was a cross-sectional survey of member Catholic Men Organization (CMO) and members of Catholic Women Organization (CWO) of Awka Diocese.

\section{Study Setting}

The study was carried out in the selected parishes in Awka Diocese, Anambra State Nigeria. And it was by the willing participants.

\section{Study Population and Sampling Strategy}

Members of Catholic Men Organization (CMO) and members of Catholic Women Organization (CWO) of Awka Diocese were selected for the study. Informed consent to take part in the study was obtained before questionnaires were administered to each participant irrespective of gender and age. Also with help of assistants' 276 participants', 127 males and 149 females were recruited for the study. Their age ranged from 24 to 98 with a mean of age of 46.13 and a standard deviation of 18.35 .

\section{Data Collection}

Index of Marital Satisfaction (IMS), Symptom Distress Checklist-90 (SCL-90) and Multidimensional Scale of Perceived Social Support (MSPSS) questionnaire were used to collect data. The sociodemographic questionnaire gave information about the participant's age, gender, years in marriage, educational status and occupation and to effectively use these instruments a pilot were conducted.

Index of Marital Satisfaction (IMS) was developed by Hudson (1982). The 25-item inventory is designed to measure the degree, severity or magnitude of the problems one spouse or partner perceived to be having in the marital relationship with his or her partner. Its focus is on the current problems which have reduced marital 
satisfaction. The scale has Alpha coefficient of .96 as obtained by Hudson (1982) and concurrent validity of .48 (Anene, 1994) by correlating Index of Marital Satisfaction with Marital Stress Inventory (Omoluabi, 1994). A total of 100 participants were used for this pilot study. This study is based in Nnewi Diocese which is made up of four Regions namely: Nnewi Region, Ozubulu Region, Ihiala Region and Amichi Region and each Region are composed of Deaneries which in turn comprises of many parishes. The researcher obtained the Alpha coefficient of .94 was obtained which is the basis for interpretation in this study, with a mean age of 52.5833 and a standard deviation of 23.44333 .

Symptom Distress Checklist-90 (SCL-90) is a psychological test that measures 10 psychological disturbances namely: Somatisation, Depression, Anxiety, Obsessive- Compulsive Disorder, Psychoticism, Neuroticism, Extroversion, Hostility and Interpersonal Sensitivity. SCL-90 was developed by Derogatis, Lipmann and Covi (1973) to measure several manifestations of psychological distress. Derogatis et al reported alpha coefficient which ranged from .77 for Psychoticism to .90 for depression. The one-week interval test-retest reliability coefficient ranged from .75 for hostility to .90 for Phobic anxiety, Erinoso (1996) reported concurrent validity which ranged from .26 for hostility to .47 for Neuroticism by correlating SCL-90 with Retirement and Stress Inventory Omoluabi (1996). The depression subscale was only used for this study which has item 32 to 44 . The researcher conducted a pilot study using a total of 120 participants drawn Nnewi Diocese which is made up of four Regions namely: Nnewi Region, Ozubulu Region, Ihiala Region and Amichi Region and each Region are composed of Deaneries which in turn comprises of many parishes. The researcher obtained alpha coefficient of .83 with a mean age of 52.5833 and a standard deviation of 23.44333
Multidimensional Scale of Perceived Social Support (MSPSS)

MSPSS is a 12-items scale for social support (Zimet, Dahlem, Zimet, \& Farley, 1988). It was framed to evaluate the perceptions of social support from three specific domains: Family, Friends and Significant Others. It has a 7-point Likert scale. The range of possible scores is 12-84. The higher the sum of the 12 items, higher the level of social support. Scale has the Cronbach alpha level of .88 . Test-retest reliability of the scale was reported to be .85 (Zimet, Dahlem, Zimet, \& Farley, 1988). Omoluabi (1996) obtained 3 weeks' test-retest reliability coefficient of .67 and divergent validity of .70 by correlating MSPSS with Index of Family Relation (Hudson, 1982). The researcher carried out a pilot study for the purpose of this study using 120 participants drawn from Nnewi Diocese. The researcher obtained alpha coefficient of .82 with a mean age of 53.2529 and a standard deviation of 8.90586.

\section{Data Analysis}

Data obtained were analysed using SPSS, multiple regression analysis, linear type was used. This was used for the specific aim of predicting values on a criterion variable from a predictor variable.

\section{Ethical Consideration}

Permission to conduct this study was obtained from the various parish priests before data collection commenced and consent letter was signed by willing participants.

\section{Study Population}

A total of 276 participants' 127 males and 149 females' participants who were members of Catholic Men Organization (CMO) and Catholic Women Organization (CWO) of Awka Diocese.

\section{Sociodemographic Characteristics}

Among the 276 married men and women were 127 males representing $18.1 \%$ and 149 females representing $21.2 \%$ of the respondents. Their age ranged from 24 to 98 with a mean of age of 46.1268 and a standard deviation of 18.34840 . Besides, among these 276 participants those that attended only Primary School were 62 representing $8.8 \%, 158$ are with SSCE 
representing $22.5 \%$ of the respondents, and 56 persons are with Degree representing $8.0 \%$ of the respondents. Years of marriage, young couples were 124 representing (17.7\%) of the participants and old couples were 152 representing (21.7\%) of the participants. On occupation, 186 persons were artisans representing $26.5 \%$ of the respondents and 90 persons were professionals representing
$39.3 \%$ of the respondents. All the participants were Christians (Catholic Denomination).

\section{Result}

The presentation of results which is done by first, presenting the demographic table of the participants, followed by summary tables of the result and then interpretations of the result hypothesis by hypothesis.

Table 1: Summary of Frequency Table of Statistics

\begin{tabular}{|c|c|c|c|c|c|c|}
\hline & & Sex & Age & $\begin{array}{c}\text { Year of } \\
\text { marriage }\end{array}$ & $\begin{array}{c}\text { Educational } \\
\text { status }\end{array}$ & Occupation \\
\hline \multirow{2}{*}{$\mathrm{N}$} & Valid & 276 & 276 & 276 & 276 & 276 \\
\cline { 2 - 7 } & Missing & 4 & 4 & 4 & 4 & 4 \\
\hline \multicolumn{2}{|c|}{ Mean } & 1.5399 & 46.1268 & 7.8949 & 6.6304 & 8.3261 \\
\hline \multicolumn{2}{|c|}{ Std. Deviation } & .49931 & 18.34840 & 7.78436 & 6.26920 & .46963 \\
\hline
\end{tabular}

Table 2: Table of regression analysis of marital dissatisfaction and social support as predictors of depression among married individuals

\begin{tabular}{|l|c|c|c|c|c|c|c|}
\hline \multirow{2}{*}{ Model } & \multicolumn{2}{|c|}{ Unstandardized coefficient } & Standardized & \multirow{2}{*}{ T } & Sig. & $95 \%$ & \\
\cline { 2 - 5 } & $\mathrm{B}$ & Stand Error & Beta & & & & \\
\hline Constant & 50.915 & 9.336 & & 5.453 & .000 & 32.481 & 69.349 \\
MSPSSFAM &.-068 & .148 & -.037 & -.463 & .644 & -.360 & .223 \\
MSPSSFRI & -.282 & .145 & -.153 & -1.941 & .054 & -.569 & .005 \\
MSPSSOTHER & -.158 & .154 & -.081 & -1.028 & .305 & -.463 & .146 \\
Index of marital satisfaction & -.099 & .093 & -.083 & -1.055 & .283 & .283 & .086 \\
\hline
\end{tabular}

Hypothesis 1: This states that marital dissatisfaction would positively and significantly predict depression among married individuals

Table 2 above, result showed that the beta weights indicate that Marital dissatisfaction $\beta=$.$.083, \mathrm{t}(-1.055)=.283, p<.05$. Therefore, hypothesis one is rejected.

Therefore, the hypothesis $\mathbf{H}_{\mathbf{1}}$ that states that marital dissatisfaction would positively and significantly predict depression in married individuals is accepted. This means that marital dissatisfaction will not predict depression in married men and women. Table 2 further shows that participant with low beta value indicates normal or adequate marital satisfaction

Hypothesis 2: Family social supports would negatively and significantly predict depression among married individuals.
Table 2 above, result showed that the beta weights indicate that MSPSSFAM $\beta=.-037, \mathrm{t}(.463)=$ $.644, p<.05$. Therefore, hypothesis one is rejected. Indicates that family social support would negatively and significantly predict depression in married individuals (beta $=-.153$ ). Therefore, the null hypothesis $\mathbf{H}_{2}$ that states that social support will not predict tendency to depression in married individuals is rejected. This implies that participant without social support will manifest depression

Hypothesis 3: Friends social supports would negatively and significantly predict depression among married individuals.

Table 2 Table 2 above, result showed that the beta weights indicate that MSPSSFRI $\beta=.-.153, \mathrm{t}$ ($.463)=.054, p<.05$. Therefore, hypothesis one is rejected.

It indicates that friends social support would negatively and significantly predict depression in 
married individuals (beta $=-.081$ ). Therefore, the hypothesis $\mathbf{H}_{3}$ that states that social support will not predict tendency to depression in married individuals is accepted. This implies that participant without social support will manifest depression

Hypothesis 4: Significant others Social supports would negatively and significantly predict depression among married individuals.

Table 2 above, result showed that the beta weights indicate that MSPSSOTHERS $\beta=$ =.-.081, $\mathrm{t}$ ($1.028)=.350, p<.05$. Therefore, hypothesis one is rejected. It indicates that others social support would negatively and significantly predict depression in married individuals (beta $=-.083$ ). Therefore, the null hypothesis $\mathbf{H 4}$ that states that social support will not predict tendency to depression in married individuals is rejected. This implies that participant without social support will manifest depression.

\section{Discussion}

This study which focussed on marital dissatisfaction and perceived social support as predictors depression among married individuals, Hypothesis 1: which stated that marital dissatisfaction will significantly predict depression among married individuals was rejected. The finding showed that marital dissatisfaction did not predict depression in married individuals (bate $=$ .032). This implies that depression is not predicated on marital dissatisfaction in married individuals.

The finding of this study is in contrast with earlier studies which implicated marital dissatisfaction in the development or causes of depression in married people, (Fincham, Beach, Herold and Osborne, 1997; Whisman, 2001). A meta-analysis of 26 cross-sectional research studies relating marital quality to depression found an effect size of -.42 for women and -.37 for men (Whisman, 2001). In addition, longitudinal research has found that marital distress is a significant predictor of subsequent depression (Dehle and Weiss, 1998; Schafer, Wickrama \& Keith 1998; Whisman
2001). Similarly, Fincham and Beach, (1999) observed in their study that both syndronal depression and depressive symptoms are strongly associated with marital distress Patient whose high levels of depression were accompanied by low marital cohesion reported the most tinnitusrelated role disability. In addition, spouse related punishing response and their interaction with depression explained an additional $15 \%$ of variance in disability beyond gender, characteristics and depression (Kiecolt-Glaser \& Newton, 2001).

Again, data from a large epidemiological study demonstrated that unhappy marriages were a potent risk factor for major depressive disorder for both men and women, associated with a 25-fold increase over untroubled marriages (Weissman, 1987). Besides, Cryne and Benazon, (2001) reported that syndromal and symptomatic depression rather precipitated marital dissatisfaction in married men and women. They also observed that individuals who experience depression in their marriage may have had their first experience with depression in their early 20s, either before or while they are in the process of selecting a mate. Bruce (1998) in a prevalence study found that $70 \%$ of those who had history of depression, separate or divorce few years after their marriage.

However, the finding of this study is supported by the findings Whisman (2001) challenged the findings of the early studies that related depression to dissatisfaction marriage arguing that those findings excluded socio-cultural factors such as ethnicity and socioeconomic status etc. of the married individual who suddenly along the line in their marriage developed depression. Truly, dissatisfaction in marriage following interpersonal theories of depression attributes it to maladaptive social roles and patterns of relationships (NelenHoeksema, 2004) however, human life is not limited to social role and patterns of relationship. Hence, the reason for this result may be found in the argument of the different theories, like Cognitive theories suggest that depression may 
result from people interpreting stressful experiences like loss of job, death of a cherished friend, siblings or parents in a negative and distorted ways, may contribute to the development of depression other than dissatisfaction in marriage. Similarly, the presence of heritable component in the individual may predispose an individual and when such individual is faced with certain challenges without a corresponding inner reinforcement such circumstances may lead to suffer from depression other than dissatisfaction in marriage. At other time, one's social position might make him or her not to feel dissatisfaction in his or her marriage. Besides, our attribution to external causes (i.e. belief that the cause of the marital problem was external factors) might also disallow the manifestation of depression even in the midst of marital dissatisfaction. Most importantly, self-appraisal which implies the way the individual perceives the marital dissatisfaction and religious orientation of the individual especially in Nigerian could be mediating factors. Hypothesis 2, which stated that social supports will not significantly predict depression among married individuals, was rejected. This finding showed that social support is a predictor of depression (beta $=-.053$ ). This finding is in support of some of the previous findings on social support and psychopathology, Mitchell and Hodson (2004) report that symptoms, particularly of depression, may resolve when social support and safety increase. Besides, Khan and Aftab (2013), in their study of marital satisfaction and perceived social support as vulnerability factors to depression observed that there is a predictive association between marital satisfaction and perceived social support; they noted that mere perception of social support is better than the actual support while predicting depression. This they noted is consistent with previous studies (Pasch, Branbury and Davila, 1997; Carel and Baucom, 1999; Xu and Burleson, 2001). When partners believe, their spouse is fully committed with them and is fully supportive, the level of security would vividly increase which in turn positively influences one's level of marital satisfaction. However, while the finding of this study shows that perceived or actual social support is a strong predictor of depression when taken alone. In African context, family ties help closely bonded families in eradicating psychological tumult by providing the sense of support or serve as a protective factor again psychological well- being of the overall family as a unit as the couple. Cotton (1999) observed that when the level of social support decreases, depression's level increases. A decline in depression resulting from stressful life events is observed when the spouse elicits supportive behaviour (Brown and Harris, 1978, Chou and Chi, 2001). Essentially, Social support may change the way we think by encouraging us to positive attribute to an otherwise negative event in life (Joiner, 2002). Lack of perceived or actual social support is not just a manifestation of depression itself; rather lack of social support contributes to the creation of depressive symptoms (Aneshensel \& Stone, 1982). Previous researches have indicated that marital dissatisfaction which leads to depression can be unhealthy both physically and psychologically (Kiecolt-Glaser \& Newton, 2001).

This result negates the precious study by McGonagle and Schilling (1992) who report that depression in married men and women is not predicated on lack of social support because not everyone in a distressed marriage as such lack of social support experience depression. Granted that the finding of this study supported that absence of social support as a predictor of depression, this result may not stand in all cases, because it failed to recognize individual's difference. Neurotic individuals are more prone to anxiety and as such more vulnerable to stress that may result in depression irrespective of the amount of social support that may surround such individual.

\section{Limitations of the Study}

This study was a cross-sectional study in which the participants were seen only once. At the 
beginning of this study, it was the intention of the researcher to select participants from all the Catholic dioceses in Onitsha ecclesiastical province. This was not possible owing to time and economic constraints. The researcher was therefore limited to parishes within the Awka Catholic diocese namely: the four (4) in each deanery randomly selected parishes from the four (4) Regions namely: Adazi Region, Akpu Region, Awka Region and Ekwulobia Region which is composed of twenty- three (23) Deaneries.

The study was further limited by the reluctance and sensitivity by some of the respondents in responding to some of the questions; despite the research's effort to explain to them that it is not meant to judge them.

The study is limited to Catholic CMO and CWO members so it could not compare to their counterpart from other denominations like: Anglican, Methodist, and new generation churches.

This work was limited to three (3) parishes randomly selected from the twenty-three (23) deaneries within the four Regions in Awka Diocese. A broader study that may cover the entire Catholic Diocese in Onitsha ecclesiastical province is recommended.

A more intensive literature review with the aid of internet was not possible due to poor power and limited access to relevant literature.

\section{Conclusion}

This research project was embarked upon to study Marital Dissatisfaction and Perceived social support as predictors of depression among married individuals. The independent variables are: Marital Dissatisfaction and Perceived social support and the dependent variables are: depression. The subjects were drawn from four (4) parishes randomly selected from the twenty-three (23) deaneries within the four Regions in Awka Diocese Among the participant's male were $18.1 \%$ (127) and female were 21.2\% (149) 127.

The review of literature covered the areas that are relevant to the study. The self evaluation questionnaire used in study was without serious modification, for it, it is already in use and tallies with the proposed hypothesis. The findings reveal that marital dissatisfaction will not predict depression in married individuals but Social support will predict depression among married individuals.

Hence, the influence of social support must always be appreciated, while we seek ways of enhancing perceive or actual social support of individual especially married individuals in their married life. Finally, this study has explored more Marital Dissatisfaction and Perceived social support as predictors of depression among married individuals and as such has added with its result to the knowledge already available on their psychological health of married individuals It is plausible that these findings have come from particular data set, yet the present study is a strong foundation upon which further research on construct validity may be based.

\section{Acknowledgement}

We appreciate Prof J, Ezeokana and Prof R, Ugokwe-Joseph for his painstaking in proof reading this work at the early stage. We appreciate Mrs Ifunaya Chima Anyika and Mr Chima Anyika for their assistance during the data collection. The various parish priests in Awka Diocese, The Executives and members of CMO and CWO for the approval and support and the participants in this are all appreciated for their understanding and free consent.

\section{Compliance with Ethical Standards}

Conflict of interest: All authors declare that they have no conflict of interest.

All participants filled the consent form to declare their their free will to participate in the study.

\section{References}

1. Akanbi, S. (2002). An investigation of the factors determining marital satisfaction among elites in Ogbomoso land. Unpublished Master's Thesis Department 
of Guidance and Counselling. University of Ibadan, Ibadan.

2. Amato, P., \& Previt, D. (2003). Peoples reasons for divorcing: Gender, Social Class, the life course and Adjustment, the Pennsylvania State University, Journal of family issues, Sage Publications 24 (5) 602-626.

3. Anene (1994) in Omoluabi, F (1994) SCL90 Manual Unpublished manuscript, Department of Psychology University of Lagos.

4. Aneshesel, C., \& Stone, J., (1982). Press and depression: A test of the buffering model of social support. Archives of General Psychiatry, 39, 1392-1396.

5. Beach, S, Fincham, F and Katz (1998) Marital therapy in the treatment $f$ depression: toward a third generation. Clinical Psychology Review, 18 (6): 63661

6. Beach, S., Katz, J., Kim, S., \& Brody, G. (2003). Prospective effects of marital satisfaction on depressive symptoms in established marriages: A dyadic model. Journal of Social and Personal Relationships, 20, 355-371.

7. Beardlee, W., Bemporad, J., Keller, M., \& Kilerman, G. (1983) Children of parents with major affective disorder: a review. The American Journal of Psychiatry, 140 (7), 825-832.

8. Brown, G., \& Harris, T., (1978). Social origins depression: A study of psychiatric disorder in women. London: Tavistock.

9. Bruce, M. (1998). Divorce and psychopathology. In B. P. Dohrenwend (Ed.), Adversity, stress, and psychopathology (pp. 219-234). New York: Oxford Press.

10. Cano, A., and O'Learvy, K. (2000). Infidelity and separations precipitate major depressive episodes and symptoms of nonspecific depression and anxiety.
Journal of consulting and clinical psychology 65,5, 774-781.

11. Carels, R., \& Baucom, D., (1999). Support in marriage: Factors associated with online perceptions of support helpfulness. Journal of family psychology, 13, 131-144

12. Chou, K., \& Chi, I., (2001). Stressful life events and depressive symptoms: Social support and sense of control as mediators or mediators? International Journal of Ageing and Human Development, 52, 155171.

13. Cotton, S., (1999) Marital status and mental health revisited; Examining them importance of risk factors and resources. Family Relations, 48(3), 225-234

14. Coyne, J., \& Benazon, N (2001). Not Agent Blue: Effects of marital functioning on depression and implications for treatment. In S. R. H. Beach (Ed.), Marital and family processes in depression: $A$ scientific foundation for clinical practice, 25-44. Washington, DC:American Psychological Association.

15. Cuijpers, P., van Straten, A., van Schaik, A., et al (2009), Psychological treatment of depression in primary care: a metaanalysis. Br J Gen Pract. 59 (559): e51-60

16. Dehle, C., \& Weiss, R. (2002). Associations between anxiety and marital adjustment. Journal of Psychology, 136, 328-338.

17. Derogatis, L, Lipman, R and Cori, L (1977) SCL-90R: administration, scoring and procedures manual. Baltimore: John Hopkins University Schol of Medicine, Clinical Psychometric Research Unit.

18. Dokpesi, A. (2013). The Challenges and Coping Strategies of Women of Emigrant Spouses. In Benin-City of Nigeria. African Journal of Social Sciences. 3, 172-185

19. Erinoso, O (1996) The sources of Stress among Nigeria retirees. Unpublished B. Sc Thesis, Department of Psychology, University of Lagos. 
20. Fincham, F and Beach, S (1999) Conflict in marriage: Implications for working couples. Annual Reviews. Psychol. 50: 4777.

21. Fincham, F., Beach, S., Harold, G., \& Osborne, L., (1997). Marital satisfaction and depression: Different casual relationships for men and women? Psychological Science, 8, 351-357.

22. Gottman, J. (1998). Psychology and the study of marital processes. Annual Review of Psychology, 49, 169-187.

23. Hashmi, H., Khurshid, M., \& Hassan, I. (2007) Marital Adjustment, Stress and Depression among Working and NonWorking Married Women. Internet Journal of Medical Update-EJOURNAL 2, 1

24. Huntley, A, Araya, R \& Salisbury, C. (2012) Group psychological therapies for depression in the community: systematic review and meta-analysis. Br J Psychiatry. 84-90. Doi: 10.1192/bjp.bp.111.092049.

25. Gabe, J., Bury, M., \& Elston, M., (2004). Key Concepts in Medical Sociology. London: Sage Glassman, A., \& Shapiro, P., (1998), Depression and the course of coronary artery disease. American Journal of psychiatry, 155, 4-11.

26. Joiner, T. (2002). Depression in its interpersonal context. In I. Gotlib \& C. Hammen (Eds), Handbook of depression (pp295-313). New York: Guildford press.

27. Khan, F., \& Aftab, S., (2013). Marital Perceived Social Support as Vulnerability factors to depression. American International Jol Social Science.2, 5.

28. Kiecolt-Glaser, J., Malarkey, W., \& Chee, M (1993). Negative behaviour during marital conflict is associated with immunological down-regulation. Psychosomatic Medicine, 33, 397-409.

29. Kiecolt-Glasser, J., \& Newton, T., (2001). Marriage and Health: His and hers. Psychological Bulletin, 129 (4) 472-503.
30. Levenson, R., Carstensen, L., \& Gottman, J. (1994). The influence of age and gender on affect, physiology, and their interrelations: A study of long term marriages. Journal of Personality and Social Psychology. 67, 56-68.

31. McGonagle, K, Schilling, E. The frequency and determinants in a community sample. Journal of Social and Personal Relationships. 1992; 9:507-524.

32. Nice (2013) Depression in children and young people. Evidence Update. NolenHoeksema, S. (2004). Abnormal Psychology ( $3^{\text {rd }}$ edition). McGraw-Hill Companies, Inc, New York.

33. Omoluabi, F (1994) SCL-90 Manual Unpublished manuscript, Department of Psychology University of Lagos.

34. Omoluabi, F (1996) Development of retirement stress inventory (RSI) Unpublished manuscript, Department of Psychology University of Lagos.

35. Pasch, L.,Bradbury, T., \& Davila, J., (1997). Gender, negative affectivity, and observed social support behaviours in marital interactions. Personal relationships, 4, 361-378.

36. Richard, P. (2004) Abnormal psychology; clinical perspective on psychological disorder. Mc Grow Hill press.

37. Schafer, R., Wickrama, K., and Keith, P., (1998). Stress in marital interaction and change in depression: A longitudinal analysis of family issues, 19,178- 594.

38. Schuller, R., \& Vidmar, N. (1992). Battered woman syndrome evidence in the courtroom. Law and Human Behaviour, 16, 273-291

39. Simonsick, E., Wallace, R., Blazer, D., \& Berkmen, L., (1995). Depressive symptomatology and hypertensionassociated morbidity and mortality in older adults. Psychosomatic Medicine, 57, 427-435. 
40. Uher R, Payne JL, Pavlova B, et al; (2013) major depressive disorder in DSM-5: I1 mplications for clinical practice and research of changes from DSM-IV. Depress Anxiety. 22. doi: 10.1002/da.22217.

41. Weissman, M. (1987) Advances in psychiatric epidemiology: Rates and risks for major depression. Am. J. Public Health. 77:445-451,

42. Whisman, M., (2001). The association between depression and marital dissatisfaction. In S.R.H. Beach (Ed.) Marital and family processes in depression: A Scientific foundation for clinical practices (pp. 3-24) Washington. DC: America Psychological Association.

43. World Health Organization (2001) The World Health Report 2001. Mental Health: New Understanding, New Hope.

44. World Health Organization (2012) World suicide prevention day 2012. http://www. Who.int/mediacentre/events/annual/woorld _suicide_prevention_day/en/_Accessed 16.6.2012

45. World Health Organization (2016) Investing in treatment for depression and anxiety leads to fourfold return. www.who.int/mediacentre/news/release/20 16/depression

46. Weissman, M. (1987) Advances in psychiatric epidemiology: Rates and risks for major depression. Am. J. Public Health. 77:445-451.

47. Xu,Y., \& Burleson B., (2001). Effects of sex, culture, support on type on perceptions of spousal social support. An Assessment of the support gap-hypothesis in early marriages. Human communication research, 27 (4), 535-566.
48. Zare, A., Hajizade, M., \& Ebrahimi, F., (2010). Influence of Social Support on Treatment of Type II Diabetes in Yazd. Journal of Shahid Sadoughi University of Medical Sciences, 18 (3):277-283.

49. Zimet, G., Dahlem, N., Zimet, S., \& Farley, G (1988). The Multidimensional Scale of perceived social support. Journal of Personality Assessment, 52, 30-41. 